PAPER

\title{
Evaluation of combination therapy using aciclovir and corticosteroid in adult patients with herpes simplex virus encephalitis
}

\author{
S Kamei, T Sekizawa, H Shiota, T Mizutani, Y Itoyama, T Takasu, T Morishima, K Hirayanagi
}

See Editorial Commentary, p 1469

J Neurol Neurosurg Psychiatry 2005;76:1544-1549. doi: 10.1136/jnnp.2004.049676

See end of article for authors' affiliations

.....................

Correspondence to: Dr S Kamei, Division of Neurology, Department of Medicine, Nihon University School of Medicine, 30-1 Oyaguchikamimachi, Itabashi-ku, Tokyo 173-8610, Japan; skamei@med.nihon-u.ac. ip

Received 14 July 2004 Revised version received 30 April 2005

Accepted 7 May 2005
Objective: Herpes simplex virus encephalitis (HSVE) is associated with significant morbidity and mortality, even with appropriate antiviral therapy. In the present investigation, the first to assess efficacy of corticosteroid treatment with aciclovir therapy in HSVE, multiple logistic regression analysis was performed of predictors of outcome in adult patients with HSVE.

Methods: A non-randomised retrospective study of 45 patients with HSVE treated with aciclovir was conducted. The patients were divided into poor and good groups based on outcome at three months after completion of aciclovir treatment. The variables evaluated were: clinical variables (sex, age, days after onset at initiation of aciclovir, Glasgow Coma Scale (GCS) at initiation of aciclovir, initial and maximum values for the cell numbers and protein concentration in the cerebrospinal fluid, and corticosteroid administration); neuroradiological variables (detection of lesions by initial cranial computed tomography and by initial magnetic resonance imaging); and one neurophysiological variable (detection of periodic lateralised epileptiform discharges on the initial electroencephalogram). Single variable logistic regression analysis was performed followed by multiple logistic regression analysis. The best set of predictors for the outcome of HSVE was estimated by stepwise logistic regression analysis.

Results: A poor outcome was evident with older age, lower GCS score at initiation of aciclovir, and no administration of corticosteroid. Patient age, GCS at initiation of aciclovir, and corticosteroid administration were found to be significant independent predictors of outcome on multiple logistic regression analysis, and these three variables also formed the best set of predictors $\left(R^{2}=0.594\right.$, $\mathrm{p}<0.0001$ ).

Conclusion: Combination therapy using both aciclovir and corticosteroid represents one of the predictors of outcome in HSVE.
$\mathrm{H}$ erpes simplex virus encephalitis (HSVE) is associated with significant morbidity and mortality, even when appropriate antiviral therapy is administered in the acute stage of the illness. ${ }^{1-3}$ Although antiviral therapy in HSVE is highly effective in reducing mortality, only fewer than half of patients with HSVE are able to return to normal health. ${ }^{1-3}$ This finding indicates the need for further improved therapeutic regimens for HSVE.

Age over 30 years, initiation of antiviral therapy more than four days after onset, a Glasgow Coma Scale (GCS) score of 6 points or less, and the detection of focal lesions by cranial computed tomography (CT) at the initiation of therapy have been reported to be predictors of a poor outcome in HSVE. ${ }^{2} 5$ These previous investigations used single variable analysis and did not assess the significance of each variable independently. The present study achieved this by employing multiple logistic regression analysis. Single variable analyses test the significance of each variable separately, whereas multiple logistic regression analysis tests the independent effect of each variable after considering the associations among the variables. There has been only one previous report estimating the outcome in HSVE by multivariable analysis. ${ }^{6}$

However, the effect of corticosteroid treatment along with administration of aciclovir on the outcome of HSVE has not yet been assessed. The percentage of patients administered corticosteroid treatment along with antiviral therapy has been given as $60-70 \%$ in prospective randomised studies estimating the efficacy of adenine-arabinoside and aciclovir treatments. ${ }^{23}$ In these previous reports, the percentage of administered corticosteroids was established to be equivalent in the two groups of different antiviral drugs, but the efficacy of corticosteroid treatment was not evaluated. The present investigation is the first study employing multiple logistic regression analysis to assess the efficacy of corticosteroid treatment with aciclovir administration in the outcome of HSVE.

\section{METHODS}

We evaluated a series of 45 patients with HSVE (19 women; mean age 46.0 years, median age 45.0 years, range 17-77) from a total of 146 patients with acute encephalitis who were initially suspected of having HSVE. The patients were admitted to six hospitals (Nihon University Itabashi Hospital, Tohoku University Hospital, and four affiliated hospitals) between 1996 and May 2004. To perform evaluations with predictors of outcome in adult HSVE patients, we established diagnostic and therapeutic protocols in 1996, before starting the present study. In our diagnostic protocol the aetiological diagnosis of HSVE was based on positive results being obtained in the following three laboratory tests: the nested polymerase chain reaction (PCR), chemiluminescence assay, ${ }^{7}$ and specific intrathecal HSV antibody synthesis, as has been described previously. ${ }^{7}$ All of the 45 patients participating in this study fulfilled this diagnostic protocol. HSVE due to HSV-1 was further confirmed by Southern blot hybridisation in all patients. The patients were treated

Abbreviations: $\mathrm{CT}$, computed tomography; GCS, Glasgow Coma Scale; HSVE, herpes simplex virus encephalitis; MRI, magnetic resonance imaging 
according to our therapeutic protocol which consisted of intravenous aciclovir ( $30 \mathrm{mg} / \mathrm{kg}$ bodyweight per day) for 14 days at the time of admission. The therapeutic protocol permitted the use of corticosteroids at the discretion of the treating physician, but it did not specify the dosage or duration of corticosteroid treatment. When used, corticosteroids were started at the initiation of aciclovir treatment. The present study therefore provides non-randomised retrospective data on the efficacy of corticosteroid with aciclovir treatment. All of the patients gave informed consent to participate in the study.

We included the following clinical parameters:

(1) sex

(2) age

(3) number of days after onset at initiation of aciclovir

(4) GCS score at initiation of aciclovir

(5) initial (maximum) leucocyte cell count in the cerebrospinal fluid (CSF)

(6) initial (maximum) CSF protein

(7) administration of corticosteroid at the acute stage

and the following neuroradiological and neurophysiological parameters:

(8) evidence of focal lesions detected by initial cranial CT

(9) evidence of focal lesions detected by initial magnetic resonance imaging (MRI)

(10) detection of periodic lateralised epileptiform discharges (PLEDs) on initial electroencephalogram (EEG).

Initial CT examinations in all patients were performed within 24 hours of admission. The initial MRI examinations were performed and the initial EEGs of all patients were examined within two days of admission. CSF samples from each patient were transferred immediately after collection to two laboratories for measurement by chemiluminescence assay (S Kamei, Division of Neurology, Department of Medicine, Nihon University School of Medicine, Tokyo) and by nested PCR (T Morishima, Department of Health Science, Nagoya University School of Medicine, Nagoya). No information about the serological data for all patients was available at the time of measurement at these laboratories; hence all CSF samples were blinded with regard to the aetiological diagnosis before they were assayed. We assessed the patients with HSVE for clinical outcomes three months after the completion of aciclovir treatment in the same way as described previously. ${ }^{8}$ The morbidity was classified into five groups as reported previously:

- normal

- mild sequelae-for patients with minor neuropsychological deficits

- moderate sequelae-for patients with limitations due to motor, speech, memory, or seizure disorders

- severe sequelae-for patients requiring supportive care

- death.

\section{Statistical analysis}

In September 2004, a statistical analyst (K Hirayanagi, Department of Hygiene and Public Health, Nihon University of Physical Education, Tokyo) at another independent institute evaluated the data for the clinical, neuroradiological, and neurophysiological parameters. The 10 variables among the three sets of parameters were evaluated as follows:
- Clinical independent variables: These were categorised as (1) $\operatorname{sex}$ (male $=0$, female $=1$ ), (2) age (years; real numbers), (3) days after onset at initiation of aciclovir (days), (4) GCS score at initiation of aciclovir, (5) initial (maximum) leucocyte cell count in the CSF $(/ \mu \mathrm{l})(0-10$, $11-100,101-300$, and $\geqslant 301$ ), (6) initial (maximum) CSF protein $(\mathrm{mg} / \mathrm{dl})(\leqslant 50,51-100$, and $\geqslant 101)$, and (7) administration of corticosteroid at the acute stage (given $=0$, not given $=1$ ). Concerning (4), values for the subtraction GCS score from 16 (1-13; value increasing according to the severity of consciousness disturbance) were entered in the statistical analysis.

- Neuroradiological and neurophysiological independent variables: These were categorised as (8) evidence of focal lesions detected by initial cranial CT (absent $=0$, present $=1$ ), (9) evidence of focal lesions detected by initial cranial MRI (absent $=0$, present $=1$ ), and (10) detection of PLEDs on the initial EEG (absent $=0$, present $=1$ ).

Based on the outcomes the patients were divided into two groups: a poor outcome (moderate to severe sequelae to death) and a good outcome (normal and mild sequelae). Dichotomous dependent variable recovery was assigned a value of 1 when the outcome was poor and 0 when the outcome was good.

SAS/STAT software (Version 8) was used for the statistical analysis. The correlation of each variable against outcome was also evaluated by Spearman's rank correlation test. Single variable logistic regression analysis was employed to examine the significance of the independent variables in relation to prognosis. Variables (5) and (6), in this single logistic regression analysis, were examined as categorical variables. Then multiple logistic regression analysis was undertaken for the variables which in the single variable logistic regression analysis had been found to be associated with a poor outcome at $\mathrm{p}<0.05$. This is in accordance with the statistical design that has been used in previous studies for outcome predictors in limited numbers of patients with neuroinfections. ${ }^{9}$ Furthermore, the interactions between age and the extracted significant variables were assessed by the multiple logistic regression analysis including the products of age and the extracted significant variables. The best set of predictors for the outcome of HSVE was also estimated by stepwise logistic regression analysis of the above 10 variables. In addition, in October to November 2004, we retrospectively collected the details of the corticosteroid treatment in the acute stage from the patients' medical records. The details included the type of corticosteroid, initial dosage of corticosteroid (converted to dosage of prednisolone), and the duration of its administration. We used Fisher's exact probability test and the Mann-Whitney U test to statistically analyse for each baseline clinical characteristic the differences between the patients who were treated with and without corticosteroid. The same tests were also used to analyse the differences in the manner of corticosteroid administration between the two hospital groups.

\section{RESULTS}

The clinical and other findings of the 45 patients with HSVE included in the present study are given in table 1. A poor outcome was noted in 19 patients $(42 \%)$. The rate of poor outcome was not significantly different between the two hospital groups (13/30 patients at Nihon University Itabashi Hospital and two affiliated hospitals $v 6 / 15$ patients at Tohoku University Hospital and two affiliated hospitals) ( $p>0.99$, Fisher's exact probability test). The baseline clinical characteristics of the two groups of patients under aciclovir treatment with and without corticosteroid administration are given in table 2 . The results of the correlation, and the single 
Table 1 Clinical and other parameters in the 45 patients with herpes simplex virus encephalitis included in the present study

\begin{tabular}{|c|c|c|c|c|c|c|c|c|c|c|c|}
\hline \multirow[b]{2}{*}{$\begin{array}{l}\text { Patient } \\
\text { no. }\end{array}$} & \multirow[b]{2}{*}{ (1) Sex } & \multirow[b]{2}{*}{ (2) $\mathrm{Age}^{*}$} & \multirow[b]{2}{*}{ (3) Dayst } & \multirow[b]{2}{*}{$\begin{array}{l}\text { (4) GCS } \\
\text { scoreł }\end{array}$} & \multicolumn{2}{|c|}{ CSF examinations } & \multirow[b]{2}{*}{$\begin{array}{l}\text { (7) Corticosteroid } \\
\text { administration** }^{\text {* }}\end{array}$} & \multicolumn{2}{|c|}{ Neuroradiological findings } & \multirow[b]{2}{*}{$\begin{array}{l}\text { (10) Detection of } \\
\text { PLEDs on EEGब|ף }\end{array}$} & \multirow[b]{2}{*}{ Outcome§§ } \\
\hline & & & & & $\begin{array}{l}\text { (5) Initial } \\
\text { leucocyte } \\
\text { cell count }\end{array}$ & $\begin{array}{l}\text { (6) Initial } \\
\text { CSF protein§ }\end{array}$ & & $\begin{array}{l}\text { (8) Detection of } \\
\text { lesion by initial } \\
\text { CTt† }\end{array}$ & $\begin{array}{l}\text { (9) Detection of } \\
\text { lesion by initial } \\
\text { MRIł‡ }\end{array}$ & & \\
\hline 1 & M & 45 & 6 & 3 & 65 & 120 & 1 & 1 & 1 & 1 & Poor (death) \\
\hline 2 & $\mathrm{~F}$ & 57 & 7 & 3 & $377(452)$ & $133(358)$ & 1 & 1 & 1 & 1 & Poor (death) \\
\hline 3 & M & 74 & 2 & 6 & 52 & 33 & 0 & 1 & 1 & 1 & Poor (moderate sequelae) \\
\hline 4 & M & 34 & 4 & 14 & 148 & 36 & 0 & 1 & 1 & 0 & Good (complete recovery) \\
\hline 5 & $\mathrm{~F}$ & 60 & 7 & 3 & $4(6)$ & 66 & 1 & 1 & 1 & 0 & Poor (severe sequelae) \\
\hline 6 & M & 19 & 10 & 7 & 149 & 120 & 0 & 1 & 1 & 1 & Good (complete recovery) \\
\hline 7 & $\mathrm{~F}$ & 27 & 13 & 3 & 4 & 77 & 0 & 1 & 1 & 0 & Good (mild sequelae) \\
\hline 8 & $\mathrm{~F}$ & 21 & 11 & 6 & 22 & 92 & 1 & 0 & 1 & 0 & Good (mild sequelae) \\
\hline 9 & M & 30 & 11 & 10 & 16 & 88 & 0 & 0 & 0 & 1 & Good (complete recovery) \\
\hline 10 & $\mathrm{~F}$ & 20 & 3 & 12 & $9(12)$ & 33 & 0 & 0 & 0 & 1 & Good (mild sequelae) \\
\hline 11 & $\mathrm{~F}$ & 24 & 4 & 12 & 362 & 40 & 1 & 0 & 0 & 0 & Good (complete recovery) \\
\hline 12 & $\mathrm{~F}$ & 34 & 5 & 13 & 820 & 398 & 1 & 0 & 0 & 0 & Good (complete recovery) \\
\hline 13 & M & 17 & 4 & 7 & 139 & 104 & 0 & 1 & 1 & 1 & Good (mild sequelae) \\
\hline 14 & M & 57 & 7 & 3 & 944 & 410 & 1 & 1 & 1 & 0 & Poor (death) \\
\hline 15 & $\mathrm{~F}$ & 28 & 5 & 7 & $4(6)$ & 77 & 0 & 1 & 1 & 1 & Good (mild sequelae) \\
\hline 16 & M & 20 & 10 & 10 & 22 & 92 & 1 & 0 & 1 & 1 & Good (complete recovery) \\
\hline 17 & M & 30 & 10 & 10 & 16 & 88 & 0 & 0 & 1 & 0 & Good (complete recovery) \\
\hline 18 & $\mathrm{~F}$ & 53 & 7 & 6 & 458 & $189(235)$ & 1 & 1 & 1 & 1 & Poor (moderate sequelae) \\
\hline 19 & $\mathrm{~F}$ & 53 & 1 & 3 & 45 & 72 & 0 & 1 & 1 & 1 & Good (mild sequelae) \\
\hline 20 & $\mathrm{~F}$ & 34 & 5 & 6 & 22 & 68 & 1 & 1 & 1 & 0 & Good (complete recovery) \\
\hline 21 & M & 34 & 3 & 13 & 22 & 86 & 1 & 1 & 1 & 0 & Good (mild sequelae) \\
\hline 22 & M & 58 & 11 & 7 & 132 & 103 & 1 & 1 & 1 & 0 & Poor (severe sequelae) \\
\hline 23 & M & 29 & 6 & 6 & 1376 & 240 & 0 & 1 & 1 & 0 & Good (complete recovery) \\
\hline 24 & M & 76 & 12 & 3 & 102 & 305 & 1 & 1 & 1 & 0 & Poor (severe sequelae) \\
\hline 25 & $\mathrm{~F}$ & 33 & 9 & 12 & 61 & 61 & 1 & 0 & 0 & 1 & Good (complete recovery) \\
\hline 26 & M & 58 & 6 & 3 & 24 & 56 & 1 & 1 & 1 & 1 & Poor (death) \\
\hline 27 & M & 56 & 2 & 8 & 503 & 37 & 0 & 0 & 1 & 1 & Good (mild sequelae) \\
\hline 28 & M & 77 & 1 & 12 & 571 & 580 & 0 & 0 & 1 & 0 & Good (mild sequelae) \\
\hline 29 & $\mathrm{~F}$ & 49 & 5 & 6 & 377 & 134 & 0 & 1 & 1 & 0 & Poor (moderate sequelae) \\
\hline 30 & $\mathrm{~F}$ & 77 & 3 & 3 & $7(63)$ & $88(104)$ & 0 & 1 & 1 & 0 & Poor (moderate sequelae) \\
\hline 31 & $\mathrm{~F}$ & 68 & 5 & 10 & 41 & 173 & 0 & 0 & 1 & 0 & Good (mild sequelae) \\
\hline 32 & M & 38 & 7 & 10 & $4(8)$ & 55 & 1 & 1 & 1 & 1 & Good (complete recovery) \\
\hline 33 & M & 39 & 7 & 3 & 70 & 72 & 0 & 1 & 1 & 0 & Poor (moderate sequelae) \\
\hline 34 & $\mathrm{~F}$ & 71 & 1 & 3 & 422 & 90 & 0 & 0 & 1 & 1 & Good (mild sequelae) \\
\hline 35 & $\mathrm{~F}$ & 72 & 10 & 12 & 128 & 85 & 1 & 0 & 1 & 0 & Poor (severe sequelae) \\
\hline 36 & M & 32 & 4 & 8 & 22 & 40 & 0 & 0 & 1 & 1 & Poor (moderate sequelae) \\
\hline 37 & M & 71 & 10 & 12 & 18 & 39 & 0 & 1 & 1 & 1 & Good (mild sequelae) \\
\hline 38 & $\mathrm{~F}$ & 66 & 12 & 11 & 95 & 74 & 1 & 1 & 1 & 1 & Poor (severe sequelae) \\
\hline 39 & M & 41 & 5 & 14 & 190 & 159 & 1 & 0 & 0 & 0 & Good (complete recovery) \\
\hline 40 & $\mathrm{~F}$ & 56 & 10 & 4 & 150 & 72 & 1 & 0 & 0 & 1 & Poor (death) \\
\hline 41 & M & 27 & 4 & 13 & $21(42)$ & $45(86)$ & 1 & 1 & 1 & 0 & Good (complete recovery) \\
\hline 42 & M & 66 & 5 & 3 & 56 & 85 & 1 & 1 & 1 & 0 & Poor (severe sequelae) \\
\hline 43 & M & 45 & 12 & 8 & $4(8)$ & $28(42)$ & 0 & 0 & 1 & 0 & Good (complete recovery) \\
\hline 44 & M & 47 & 6 & 3 & $15(20)$ & 240 & 1 & 1 & 1 & 1 & Poor (moderate sequelae) \\
\hline 45 & M & 45 & 10 & 3 & 60 & 84 & 0 & 1 & 1 & 0 & Poor (moderate sequelae) \\
\hline \multicolumn{12}{|c|}{ *Age in years. } \\
\hline \multicolumn{12}{|c|}{ †Days after onset at initiation of aciclovir. } \\
\hline \multicolumn{12}{|c|}{ ‡GCS score at initiation of aciclovir. } \\
\hline \multicolumn{12}{|c|}{ 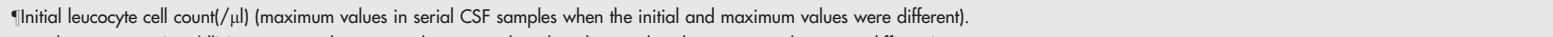 } \\
\hline \multicolumn{12}{|c|}{ §Initial CSF protein (mg/dl) (maximum values in serial CSF samples when the initial and maximum values were different); } \\
\hline ††Detec & ction of les & on by initic & ial computed & tomograp & $y(C T): 0=a b s$ & $1=$ present. & & & & & \\
\hline $\begin{array}{l}\ddagger \ddagger \text { Detec } \\
1=\text { pres }\end{array}$ & $\begin{array}{l}\text { ction of les } \\
\text { sent. }\end{array}$ & on by initic & ial magnetic & resonance & maging (MRI): & absent, $1=$ pres & nt. $\uparrow$ Detection of $p$ & eriodic lateralized & pileptiform dischar & (PLEDs) on electroe & cephalogram (EEG): 0 = absent \\
\hline *Cortic & osteroid a & Aministratio & on: $0=$ given & $1=$ not $g$ & & & & & & & \\
\hline$\S \S$ Outcc & ome at $3 n$ & onths after & completion & of aciclov & treatment. & & & & & & \\
\hline GCS, G & Slasgow $C_{C}$ & ma Scale; & ; CSF, cereb & rospinal flu & & & & & & & \\
\hline
\end{tabular}

and multiple logistic regression analyses in relation to outcome are summarised in table 3. The independent variables that were significantly related to the outcome of HSVE in the multiple logistic regression analysis included patient age, GCS score at initiation of aciclovir, and corticosteroid administration in the acute stage (see table 3 ). The best set of predictors for the outcome of HSVE as estimated by stepwise logistic regression analysis of the 10 variables included patient age, GCS score at initiation of aciclovir, and corticosteroid administration $\left(\mathrm{R}^{2}=0.594\right.$, $\mathrm{p}<0.0001)$. No interactions were found between age and corticosteroid administration, or between age and GCS. A poor outcome was thus evident in patients with older age, lower GCS scores, and no corticosteroid administration in the acute stage (see table 3). Details of the manner of corticosteroid administration in the 22/45 patients (treated with corticosteroids) are presented in table 4. Corticosteroids were administered at the same time as the initiation of aciclovir treatment. Dexamethasone was given to $82 \%$ of patients and prednisolone to $18 \%$. The initial dosage of corticosteroid, converted to the dosage of prednisolone, ranged from $40.0 \mathrm{mg} /$ day to $96.0 \mathrm{mg} /$ day (mean $64.6 \mathrm{mg} /$ day; median, $64.0 \mathrm{mg} /$ day). The duration of corticosteroid treatment ranged from 2 days to 6 weeks (mean 13.6 days; median 6.0 days), during which time the corticosteroid dosage was tapered off gradually when it had been administered for more than seven days. These differences between hospitals in the manner of corticosteroid administration were not statistically significant (table 4). 
Table 2 Baseline clinical characteristics of the patient groups under aciclovir therapy with and without concomitant corticosteroid administration

\begin{tabular}{|c|c|c|c|}
\hline & $\begin{array}{l}\text { Corticosteroid } \\
\text { administration } \\
(n=22)\end{array}$ & $\begin{array}{l}\text { No corticosteroid } \\
\text { administration } \\
(\mathbf{n}=23)\end{array}$ & $\begin{array}{l}\text { Difference } \\
\text { between the } \\
\text { two groups* }\end{array}$ \\
\hline (1) Male (\%) & 64 & 52 & NS \\
\hline $\begin{array}{l}\text { (2) Age in years (minimum, mean, median, and } \\
\text { maximum) }\end{array}$ & $\begin{array}{l}17.0,45.0,42.0 \\
77.0\end{array}$ & $\begin{array}{l}20.0,46.8,47.0 \\
76.0\end{array}$ & NS \\
\hline $\begin{array}{l}\text { (3) Days after onset at initiation of aciclovir } \\
\text { (minimum, mean, median, and maximum) }\end{array}$ & $1.0,5.9,5.0,13.0$ & $3.0,7.3,7.0,12.0$ & NS \\
\hline $\begin{array}{l}\text { (4) GCS score at initiation of aciclovir } \\
\text { (minimum, mean, median, and maximum) }\end{array}$ & $3.0,7.3,7.0,14.0$ & $3.0,7.5,6.0,14.0$ & NS \\
\hline $\begin{array}{l}\text { (5) Initial and <maximum }>\text { leucocyte cell count } \\
(/ \mu l) \text { in CSF } \\
\text { (minimum, mean, median, and maximum) }\end{array}$ & $\begin{array}{l}4,184,49,1376 \\
<4,187,56,1376>\end{array}$ & $\begin{array}{l}4,178,65,944 \\
<6,178,65,944>\end{array}$ & NS \\
\hline $\begin{array}{l}\text { (6) Initial and <maximum }>\text { CSF protein }(\mathrm{mg} / \mathrm{dl}) \\
\text { (minimum, mean, median, and maximum) }\end{array}$ & $\begin{array}{l}28,106,81,580 \\
<33,107,81,580>\end{array}$ & $\begin{array}{l}40,132,86,410 \\
<40,145,86,410>\end{array}$ & NS \\
\hline (8) Detection of lesion by initial CT (\%) & 59 & 65 & NS \\
\hline (9) Detection of lesion by initial MRI (\%) & 91 & 78 & NS \\
\hline (10) Detection of PLEDs on EEG (\%) & 50 & 43 & NS \\
\hline
\end{tabular}

*Statistical differences between the two groups were evaluated by Fisher's exact probability test and the MannWhitney U test.

CSF, cerebrospinal fluid; CT, cranial computed tomography; EEG, electroencephalogram; GCS, Glasgow Coma Scale; MRI, magnetic resonance imaging; NS, not significant; PLEDs, periodic lateralized epileptiform discharges.

\section{DISCUSSION}

Most of the previous results for predictors of outcome in HSVE have been based on between-group comparative analysis-for example, Wilcoxon's two sample test, $\chi^{2}$ analysis, or Fisher's exact two tailed test. ${ }^{1-4}$ Cut-off values for each of the predictors were determined arbitrarily in these studies. An important problem thus remains: estimation of the associations among the predictors of the outcome of HSVE. One recent report based on multivariable analysis in
85 patients with HSVE indicated that a Simplified Acute Physiology Score II of 27 or more and a delay of more than two days between admission to hospital and initiation of aciclovir therapy were predictors of a poor outcome in HSVE. ${ }^{6}$ Previously reported predictors such as patient age and GCS score at initiation of aciclovir were not identified as significant predictors. Although the number of patients was limited this previous study investigated numerous factors as predictors of outcome in HSVE. Furthermore, the time of

Table 3 Results for the estimation of predictors of outcome in herpes simplex encephalitis by single and multiple logistic regression analyses

\begin{tabular}{|c|c|c|c|c|c|c|}
\hline \multirow[b]{2}{*}{ Variable } & \multirow[b]{2}{*}{ Unit of increase } & \multirow{2}{*}{$\begin{array}{l}\text { Spearman's rank } \\
\text { correlation against } \\
\text { outcome }\end{array}$} & \multicolumn{2}{|l|}{ Single logistic regression analysis } & \multicolumn{2}{|c|}{ Multiple logistic regression analysis } \\
\hline & & & Odds ratio $(95 \% \mathrm{Cl})$ & p value & Odds ratio $(95 \% \mathrm{Cl})$ & p value \\
\hline (1) Sex & NA & 0.266 & $0.992(0.30$ to 3.29$)$ & 0.989 & - & - \\
\hline (2) Age & 1 year & 0.605 & $1.075(1.03$ to 1.12$)$ & $0.001^{*}$ & $1.088(1.02$ to 1.16$)$ & $0.006^{*}$ \\
\hline $\begin{array}{l}\text { (3) Days after onset at initiation } \\
\text { of aciclovir }\end{array}$ & 1 day & 0.305 & $1.097(0.92$ to 1.31$)$ & 0.144 & - & - \\
\hline $\begin{array}{l}\text { (4) Modified value of GCS score at } \\
\text { initiation of aciclovirt }\end{array}$ & 1 score & 0.602 & 1.424 (1.14 to 1.77$)$ & $0.002^{*}$ & 1.452 (1.08 to 1.95$)$ & $0.014^{*}$ \\
\hline $\begin{array}{l}\text { (5) Initial leucocyte cell count in CSF } \\
\text { (maximum values in serial CSFs) }\end{array}$ & $\begin{array}{l}0-10 \\
11-100 \\
101-300 \\
\geqslant 301 / \mu 1\end{array}$ & $0.245(0.284)$ & $\begin{array}{l}1.00 \text { (reference) } \\
0.200 \text { (0.02 to } 2.03)(0.275(0.03 \text { to } 2.90)) \\
0.200(0.02 \text { to } 2.58)(0.250(0.02 \text { to } 3.34)) \\
0.300 \text { (0.03 to } 3.63)(0.375(0.03 \text { to } 4.71))\end{array}$ & $\begin{array}{l}0.566 \\
(0.719)\end{array}$ & - & - \\
\hline $\begin{array}{l}\text { (6) Initial CSF protein } \ddagger \\
\text { (maximum values in serial CSFs) }\end{array}$ & $\begin{array}{l}\leqslant 50 \\
51-100 \\
\geqslant 101 \mathrm{mg} / \mathrm{dl}\end{array}$ & $0.253(0.246)$ & $\begin{array}{l}1.00 \text { (reference) } \\
0.444(0.07 \text { to } 2.74)(0.650(0.10 \text { to } 4.18)) \\
0.292(0.04 \text { to } 1.94)(0.311(0.05 \text { to } 2.11))\end{array}$ & $\begin{array}{l}0.441 \\
(0.388)\end{array}$ & - & - \\
\hline (7) Corticosteroid administration & $\begin{array}{l}0=\text { given } \\
1=\text { not given }\end{array}$ & 0.521 & 3.467 (0.99 to 12.09$)$ & $0.041^{*}$ & $8.964(1.13$ to 70.99$)$ & $0.038^{*}$ \\
\hline (8) Detection of lesion by initial CT & $\begin{array}{l}0=\text { absent } \\
1=\text { present }\end{array}$ & 0.562 & $6.222(1.45$ to 26.65$)$ & $0.044^{*}$ & $3.690(0.43$ to 31.85$)$ & 0.235 \\
\hline (9) Detection of lesion by initial MRI & $\begin{array}{l}0=\text { absent } \\
1=\text { present }\end{array}$ & 0.567 & 5.400 (0.59 to 49.27$)$ & 0.135 & - & - \\
\hline (10) Detection of PLEDs on EEG & $\begin{array}{l}0=\text { absent } \\
1=\text { present }\end{array}$ & 0.269 & $1.050(0.32$ to 3.44$)$ & 0.936 & - & - \\
\hline
\end{tabular}

*Statistically significant $(p<0.05)$

†Subtraction GCS score from 16

$\ddagger$ The values of (5) and (6) were arbitrarily categorised as above based on our clinical experience.

CSF, cerebrospinal fluid; CT, cranial computed tomography; EEG, electroencephalogram; GCS, Glasgow Coma Scale; MRI, magnetic resonance imaging; NA, not applicable; PLEDs, periodic lateralised epileptiform discharges. 
Table 4 Details of corticosteroid treatments given along with aciclovir treatment in the acute stage of herpes simplex virus encephalitis

\begin{tabular}{|c|c|c|}
\hline & & $\begin{array}{l}\text { Difference } \\
\text { between }(A) \\
\text { and }(B)^{*}\end{array}$ \\
\hline Patients given corticosteroids ( $\mathrm{n} / \mathrm{N}(\%)$ ) & $\begin{array}{l}22 / 45(49) \\
(A) \dagger 15 / 30(50) \\
(B) \ddagger 7 / 15(47)\end{array}$ & NS \\
\hline Time of initiation of corticosteroid treatment & \multicolumn{2}{|c|}{$\begin{array}{l}\text { All patients were administered corticosteroid at the } \\
\text { same time as the initiation of aciclovir treatment }\end{array}$} \\
\hline \multicolumn{3}{|l|}{ Type of corticosteroid (n/N (\%)) } \\
\hline Dexamethasone & $\begin{array}{l}18 / 22(82) \\
\text { (A) } 12 / 15(80) \\
\text { (B) } 6 / 7(86)\end{array}$ & NS \\
\hline Prednisolone & $\begin{array}{l}4 / 22(18) \\
\text { (A) } 3 / 15(20) \\
\text { (B) } 1 / 7(14)\end{array}$ & NS \\
\hline $\begin{array}{l}\text { Initial dosage of corticosteroid converted to dosage of } \\
\text { prednisolone (mean, median, distribution) }\end{array}$ & $\begin{array}{l}64.6,64.0 \mathrm{mg} / \text { day, } 40.0-96.0 \\
\text { (A) } 67.9,64.0,48.0-96.0 \\
\text { (B) } 61.7,64.0,40.0-96.0\end{array}$ & NS \\
\hline $\begin{array}{l}\text { Duration of corticosteroid treatment } \\
\text { (mean, median, distribution) }\end{array}$ & $\begin{array}{l}13.6,6.0 \text { days, } 2.0-42.0 \\
\text { (A) } 13.9,3.0,3.0-42.0 \\
\text { (B) } 12.0,8.0,2.0-35.0\end{array}$ & NS \\
\hline \multicolumn{3}{|c|}{$\begin{array}{l}\text { *Statistical differences between the two different hospital groups were evaluated by Fisher's exact probability test or } \\
\text { the Mann-Whitney U test. } \\
\text { †(A) Nihon University Itabashi Hospital and two affiliated hospitals. } \\
\text { †(B) Tohoku University Hospital and two affiliated hospitals. } \\
\text { NS, not significant. }\end{array}$} \\
\hline
\end{tabular}

initiation of aciclovir after admission, and both the duration and the dosage of aciclovir in each patient were variable. ${ }^{6}$ In our study, the time of initiation of aciclovir after admission, and both the duration and the dosage of aciclovir in each patient with HSVE were uniform and comparable. Significant predictors become difficult to detect as the number of variable factors increases, particularly when the numbers of patients are limited. We therefore limited our analysis to 10 variable factors which included previously reported predictors $^{1-4}$ based on between-group comparative analysis. Our results, based on multiple logistic regression analysis showed that patient age, GCS score at initiation of aciclovir, and corticosteroid administration in the acute stage of HSVE were significant predictors of outcome in 45 adult patients with HSVE. There were no obvious interactions between age and corticosteroid administration, or between age and GCS. The duration from onset of HSVE to the initiation of aciclovir treatment, and the detection of focal lesions by cranial CT at the initiation of therapy were not significant predictors as estimated by the multiple logistic regression analysis. The possible reasons for the lack of significance for these two factors may be, firstly, the number of patients in our study might not have been sufficient to allow detection as significant predictors, and secondly, the two factors were dependent on other predictors such as the degree of consciousness disturbance indicated by the GCS score at the initiation of aciclovir; therefore the two factors were not independent predictors of outcome in HSVE by themselves.

A notable finding of our study is that corticosteroid administration in the acute stage of HSVE represented one of the significant independent predictors of outcome in HSVE. The exact effectiveness of such combination therapy in HSVE has not yet been established. However, corticosteroids have been administered empirically with aciclovir treatment in some patients to improve brain oedema. There have been recent reports about the effects of corticosteroid administration with aciclovir treatment in an animal model of HSVE. ${ }^{10}{ }^{11}$ The data indicate that the HSV viral load of the brain tissue of animals treated with both aciclovir and corticosteroid was similar to that of the brain tissue of the animals which were treated with aciclovir alone. These studies also revealed that corticosteroids do not inhibit the antiviral action of aciclovir and may decrease the extent of HSVE infection. ${ }^{111}$ Furthermore, it has been suggested that a host immune response associated with HSVE, such as that involving cytokines, ${ }^{12}$ could play some role in the outcome of HSVE based on the findings of an in vitro experimental study on infection with HSV.

The pharmacological mechanism of corticosteroid treatment in the acute stage of HSVE may thus involve not only improvement of brain oedema but also regulation of the host immune response associated with the acute stage of HSVE. The present investigation is the first to provide statistical evidence that combination therapy using both aciclovir and corticosteroid can achieve a better outcome in adult patients with HSVE. Our study revealed three independent variables based on a multivariable regression analysis of the variables which had been found to be significant in the single variable analysis. However, multivariable regression analysis using all 10 variables is needed to achieve greater reliability, which will be possible when the number of recruited patients is sufficiently increased. Further investigations including clinical prospective randomised controlled studies are also required to determine the optimal type, dosage, and duration of corticosteroid administration.

\section{ACKNOWLEDGEMENTS}

We are indebted to Dr Y Sakai, Department of Internal Medicine, Surugadai Nihon University Hospital, Tokyo, Japan, Dr Y Tada, Department of Neurology, Eisei Hospital, Tokyo, Japan, and Dr T Yoshizawa, Division of Internal Medicine, Kanamecho Hospital, Tokyo, Japan, for providing the CSF samples and details of the patient data for some of our registered HSVE patients.

\section{Authors' affiliations}

S Kamei, H Shiota, T Mizutani, T Takasu, Division of Neurology, Department of Medicine, Nihon University School of Medicine, Tokyo, Japan 
T Sekizawa, Department of Health Science, Yamagata Prefectural University of Health Science, Yamagata-shi, Japan

Y Itoyama, Department of Neurology, Tohoku University School of Medicine, Seiryo-cho, Aoba-ku, Sendai-shi, Japan

T Morishima, Department of Health Science, Nagoya University School of Medicine, Higashi-ku, Nagoya-shi, Japan

K Hirayanagi, Department of Hygiene and Public Health, Nihon University of Physical Education, Tokyo, Japan

This study was supported by a grant from the Ministry of Education, Culture, Sports, Science, and Technology for the promotion of the industry-university collaboration at Nihon University, Japan, and a grant for scientific research from the Alumni Association of Nihon University School of Medicine.

Competing interests: none declared

\section{REFERENCES}

1 Whitley RJ, Lakeman F. Herpes simplex virus infections of the central nervous system: therapeutic and diagnostic considerations. Clin Infect Dis 1995;20:414-20.

2 Whitley RJ, Alford CA, Hirsh MS, et al. Vidarabine versus acyclovir therapy in herpes simplex encephalitis. N Engl J Med 1986;314:144-9.

3 Sköldenberg B, Forsgren M, Alestig K, et al. Acyclovir versus vidarabine in herpes simplex encephalitis: randomised multicentre study in consecutive Swedish patients. Lancet 1984;2:707-11.
4 Morawetz RB, Whitley RJ, Murphy DM. Experience with brain biopsy for suspected herpes encephalitis: a review of forty consecutive cases. Neurosurgery 1983; 12:654-7.

5 Marton R, Gotlieb-Steimatsky T, Klein C, Arlazoroff A. Acute herpes simplex encephalitis: clinical assessment and prognostic data. Acta Neurol Scand 1996;93:149-55

6 Raschilas F, Wolff $M$, Delatour $F$, et al. Outcome of and prognostic factors for herpes simplex encephalitis in adult patients: results of a multicenter study. Clin Infect Dis 2002;35:254-60.

7 Kamei S, Takasu T, Morishima T, et al. Comparative study between chemiluminescence assay and two different sensitive polymerase chain reactions on the diagnosis of serial herpes simplex virus encephalitis. I Neurol Neurosurg Psychiatry 1999;67:596-601.

8 Whitley RJ, Cobbs CG, Alford CA, et al. Diseases that mimic herpes simplex encephalitis: diagnosis, presentation and outcome. JAMA 1989:262:234-9.

9 Misra UK, Kalita J, Roy AK, et al. Role of clinical, radiological, and neurophysiological changes in predicting the outcome of tuberculous meningitis: a multivariable analysis. J Neurol Neurosurg Psychiatry 2000;68:300-3.

10 Thompson KA, Blessing WW, Wesselingh SL. Herpes simplex replication and dissemination is not increased by corticosteroid treatment in a rat model of focal herpes encephalitis. J Neurovirol 2000;6:25-32.

11 Meyding-Lamade UK, Oberlinner C, Rau PR, et al. Experimental herpes simplex virus encephalitis: a combination therapy of acyclovir and glucocorticoids reduces long-term magnetic resonance imaging abnormalities. J Neurovirol 2003;9:1 18-25.

12 Oshima M, Azuma H, Suzutani T, et al. Direct and mononuclear cell mediated effects on interleukin 6 production by glioma cells in infection with herpes simplex virus type 1. J Med Virol 2001;63:252-8. 